\title{
Modelling of operation of a stationary energy storage device in metro rail transport for selection of its parameters
}

\author{
Petru Valentin Radu ${ }^{1, *}$, and Adam Szeląg ${ }^{1}$ \\ ${ }^{1}$ Warsaw University of Technology, Institute of Electric Power Engineering, Electric Traction Division, \\ ul. Koszykowa 75, 00-662, Warsaw, Poland
}

\begin{abstract}
The paper presents a Simulink model of a DC metro traction supply system with a stationary energy storage device (SESD). The simulation model consists of traction substations, a train model, and an energy storage device (ESD) with supercapacitors (SC). A new energy management strategy considering the line voltage and current, SC state of charge (SOC) and SC charging and discharging current is proposed. This method can improve the energy savings and manage the remaining energy. Simulation results provided in this paper justify the control method. The proposed model can be used with different ESD, such as batteries.
\end{abstract}

\section{Introduction}

In 2014, energy needed for transportation was around 24 $\%$ in the United States of the overall energy consumption [1]. Nowadays most of the electrical vehicles have the capability to return the braking energy to the traction system [2]. Reutilizing the vehicle braking energy can reduce the transportation costs, power needed for the traction system and the carbon footprint. The key to saving more energy is the optimal design for the energy storage devices including: selection of an appropriate type, location, size and energy management strategy.

During the last few years, a large number of energy management strategies were proposed in different papers for example: adaptive fuzzy logic strategy [3], real time optimization [4], global optimization [5], rule based strategy [6], genetic algorithm strategy [7] and load power strategy [8, 13]. The energy management strategies can theoretically lower the energy consumption up to $20 \%$ and reduce the size of the energy storage devices $[9,10]$. Experimental tests with ESD have justified their application in urban transport [14]. On the other hand, these methods have several drawbacks, e.g. the complexity of the solution and the input data needed obtained from additional costly equipment in the vehicle for its location, velocity etc. In this paper a new management strategy is presented and tested on a simulation model build in Matlab / Simulink for the SESD on metro transport.

\section{Matlab / Simulink model of a traction supply system with SESD}

A simulation model was built in Matlab / Simulink, for a light rail power supply system which includes $15 \mathrm{kV} \mathrm{AC}$ power supply source, $750 \mathrm{~V}$ DC traction substations with transformer - rectifier, trains and SESD with SC.

\subsection{Traction substation model}

In Poland the power to the metro traction supply is provided from District Point Supply (RPZ - Rejonowych Punktow Zasilania). The transformer rectifier substations convert the $15 \mathrm{kV}, 50 \mathrm{~Hz}$ to $750 \mathrm{~V} \mathrm{DC}$ which is supplying the metro cars by third rail. The metro supply is "dual feed" on AC and DC side to provide backup power in the event of a fault.

Figure 1 presents the polish metro supply configuration.
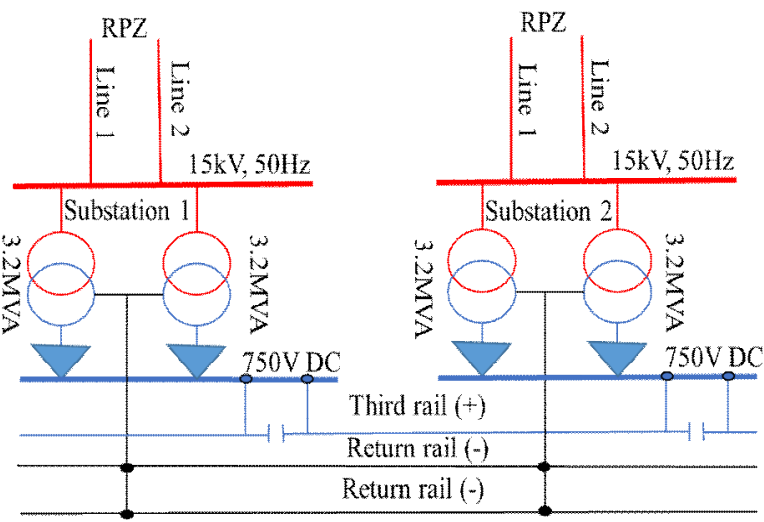

Fig. 1. Metro 750V DC supply configuration.

The metro supply configuration from figure 1 was built in Simulink. The model consists of a three phase power source (PS), three phase transformer - rectifier $\mathrm{Y} / \mathrm{D}$ connection (TR).

In table 1 is given the assumed specification for the power supply model.

\footnotetext{
* Corresponding author: petru.radu@ee.pw.edu.pl
} 
Table 1. Traction supply simulation parameters.

\begin{tabular}{|l|l|l|}
\hline Parameter & Unit & Quantity \\
\hline PS Nominal Power & MVA & 20 \\
\hline PS Voltage & $\mathrm{kV}$ & $15(50 \mathrm{~Hz})$ \\
\hline TR Nominal Power & MVA & 3.2 \\
\hline TR Primary Voltage & $\mathrm{kV}$ & $15(50 \mathrm{~Hz})$ \\
\hline TR Secondary DC Voltage & $\mathrm{V}$ & 750 \\
\hline
\end{tabular}

\subsection{Line model}

The running rail and the third rail are simulated by linear resistance and considered pure resistive. The running rail has an assumed resistance of $35.7 \mathrm{~m} \Omega / \mathrm{km}$ and the third rail has an assumed resistance of $11.7 \mathrm{~m} \Omega / \mathrm{km}$.

\subsection{Train model}

A simplified model of a train was built using a controlled current source and the input signal for the source is provided with a Signal Builder. In the Signal Builder the values of the assumed train current with respect to time is provided. Real values of the train current can be provided to the model.

Figure 2 shows the assumed train currents used for the simulation purposes. For the train model all 3 stages were considered: acceleration, coasting, braking with regeneration. A simulation time of $200 \mathrm{~s}$ was proposed to verify the Simulink model.

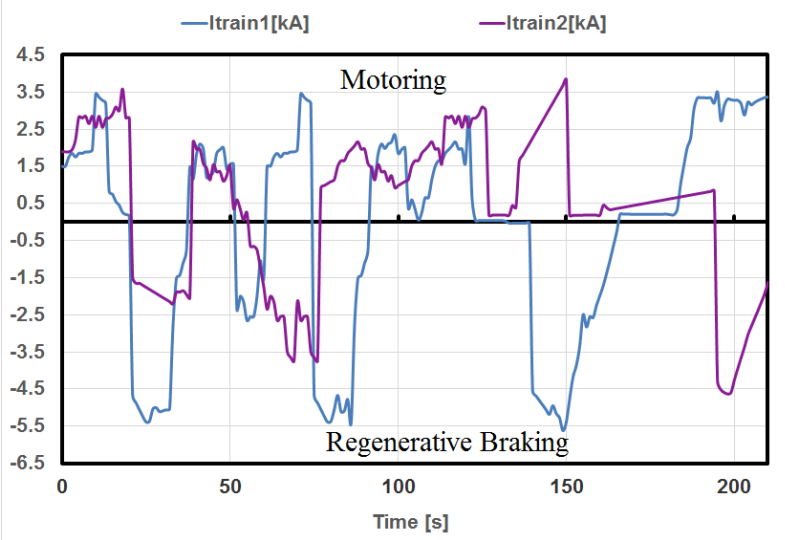

Fig. 2. Train current.

If the train is braking with regeneration and there is no other train or SESD to absorb the energy the voltage in the third rail will increase and exceed the limits. European Standard (EN) 50163 [11] regulates the maximum and minimum allowable voltage for the $750 \mathrm{~V}$ DC system as below:

- Un $=750 \mathrm{~V}$ DC - nominal voltage;

- Umin $1=500 \mathrm{~V}$ DC - lowest permanent voltage;

- Umax 1 = 900 V DC - highest permanent voltage;

- Umax2 $=1000 \mathrm{~V}$ DC - highest non-permanent voltage;

To prevent the overvoltage, a braking system with braking resistor was implemented for the train. A control system using Matlab Function and compliant to the EN 50163 standard was designed. The input values are the train voltage values measured by a voltage meter. The output consists of control signals to ideal switches which in turn switch OFF or ON different braking resistance $(\mathrm{Rb})$ according with third rail voltage as per table 2 . The 1 means that the braking resistor is switched $\mathrm{ON}$ and the 0 means that is switched OFF.

Table 2. Braking logical table.

\begin{tabular}{|c|c|c|c|c|c|}
\hline $\begin{array}{c}\text { Train } \\
\text { Voltage } \\
{[\mathbf{V}]}\end{array}$ & $\begin{array}{c}\mathbf{R b}_{\mathbf{1}} \\
{[\mathbf{0 . 5} \mathbf{\Omega}]}\end{array}$ & $\begin{array}{c}\mathbf{R b}_{\mathbf{2}} \\
{[\mathbf{0 . 4} \mathbf{\Omega}]}\end{array}$ & $\begin{array}{c}\mathbf{R b}_{\mathbf{3}} \\
{[\mathbf{0 . 3} \mathbf{\Omega}]}\end{array}$ & $\begin{array}{c}\mathbf{R b}_{\mathbf{4}} \\
{[\mathbf{0 . 2} \mathbf{\Omega}]}\end{array}$ & $\begin{array}{c}\mathbf{R b}_{\mathbf{5}} \\
{[\mathbf{0 . 1} \mathbf{\Omega}]}\end{array}$ \\
\hline$\geq 950$ & 1 & 0 & 0 & 0 & 0 \\
\hline$\geq 1050$ & 1 & 1 & 0 & 0 & 0 \\
\hline$\geq 1100$ & 1 & 1 & 1 & 0 & 0 \\
\hline$\geq 1150$ & 1 & 1 & 1 & 1 & 0 \\
\hline$\geq 1270$ & 1 & 1 & 1 & 1 & 1 \\
\hline
\end{tabular}

\subsection{SESD model}

The SESD model consist, of supercapacitors, DC-DC charging converter and DC-DC load converter. The Maxwell (125 V module) SC parameters are presented in table 3.

Table 3. Maxwell SC parameters [12].

\begin{tabular}{|l|c|}
\hline Parameter & Value \\
\hline Rated Voltage & $750 \mathrm{~V}$ \\
\hline Modules in series & 6 \\
\hline Modules in paralel & 3 \\
\hline Capacitance & $189 \mathrm{~F}$ \\
\hline Energy & $40 \mathrm{MJ}$ \\
\hline Maximum Charge / Discharge Current & $6 \mathrm{kA}$ \\
\hline
\end{tabular}

The SC voltage values need to be between $40 \%(300$ $\mathrm{V})$ and $100 \%(750 \mathrm{~V})$ of the nominal value in order to maintain converters operation. The SC state of charge was set between $40 \%$ and $100 \%$ for the simulation and the maximum SC charging / discharging current has to be kept below $6 \mathrm{kA}$ in order to protect it.

An energy management control system considering the third rail voltage and current, regenerated power, load power, SC SOC, SC charging current and SC discharging current was designed and presented in figure 3.

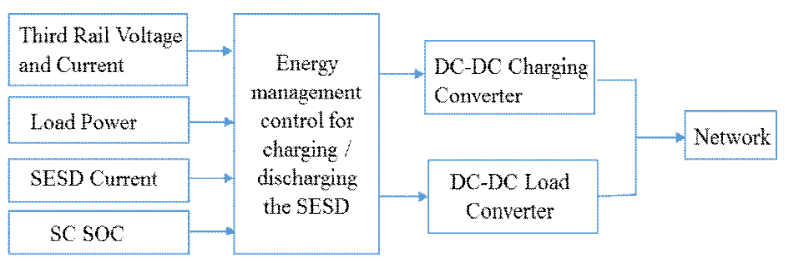

Fig. 3. SESD energy management system.

The power control of SESD charging and discharging cycles is based on the line voltage as shown in figure 4 .

\subsubsection{DC-DC charging converter}

The DC-DC charging converter was built with ideal switches. A diode was used to make the current to flow from the braking train to the SESD. An inductor was designed for keeping the charging current stabile. 


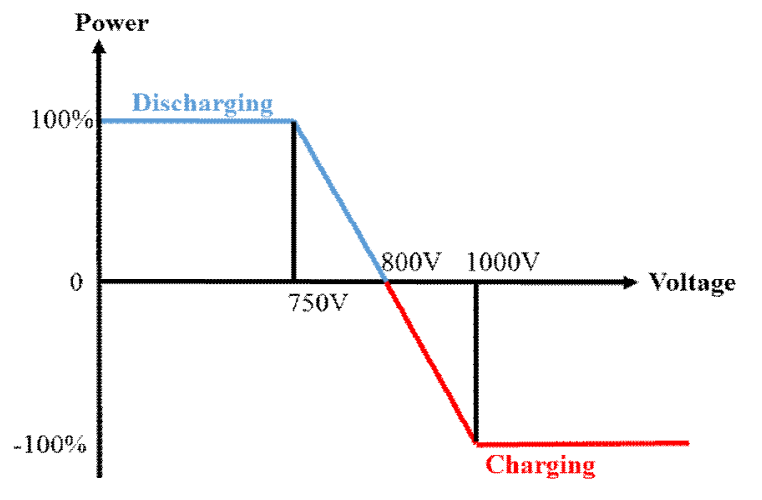

Fig. 4. Power control diagram for SESD.

The block marked " $\mathrm{X}$ " in figure 5 and figure 7 is used for multiplication of the logical values of "ESD charging / discharging" for all decision blocks.

The SESD charging control have been implemented as below:

- The third rail voltage (UL) and current (IL) is measured. The regenerated power (PL) is calculated. The train braking with regenerations is detected when the third rail voltage is higher than $800 \mathrm{~V}$ and the power is lower than $100 \mathrm{~W}$. The SESD is charging if the network demand power is negative $(<0 \mathrm{~W})$ which means that the train is braking with regeneration. To avoid fluctuations in the control block the control power for SESD charging was selected arbitrary to be $100 \mathrm{~W}$.

- SESD current (ISESD) is measured and compared with the sum current of the running trains. This function allows the SESD to charge only from the regenerative energy and not from the substations.

- SESD current (ISESD) is measured and compared with the maximum allowable charging current $6 \mathrm{kA}$. This restrictions keeps the discharge current below the maximum value in order to protect the SC.

- SC state of charge (SOC) is measured and when reaches $100 \%$ the SESD stops from charging.

If all conditions are met then SESD will charge from the third rail $(\mathrm{SESD}$ charging $=\mathrm{ON})$.

The energy management strategy flowchart for the charging control is shown in figure 5.

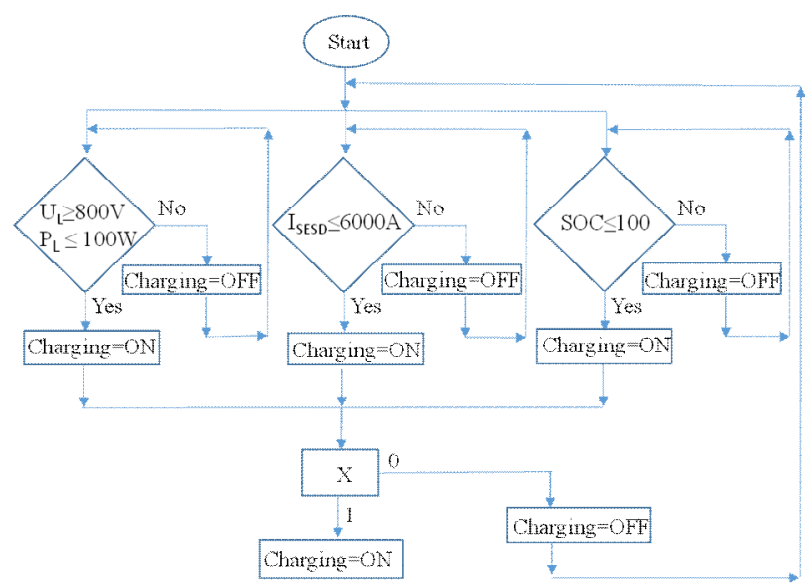

Fig. 5. Energy management strategy for charging the SESD.

\subsubsection{DC-DC load converter}

A Cuk converter is used for the DC-DC load converter described and tested in [13]. The converter uses a closed loop cascade control with two PI regulators for load current and output voltage.

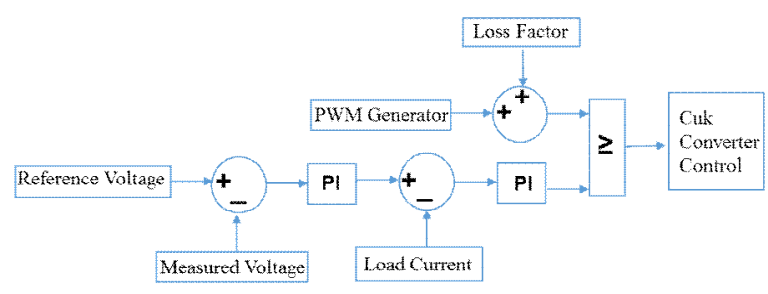

Fig. 6. Control architecture for the DC-DC load converter [13].

The controller objective is to stabilize the current supplied by the SC during sudden changes in load current and keep the output voltage constant to $750 \mathrm{~V}$.

The DC third rail voltage is measured and compared with the voltage threshold value $750 \mathrm{~V}$. If the third rail voltage is lower than $750 \mathrm{~V}$ the SESD provides with the rest of the power. To prevent PI regulators saturation during the SESD charging, they are enabled by the energy management load control.

The SESD load control has been implemented as below:

- The third rail voltage (UL) and current (IL) is measured. The load power (PL) is calculated and compared against the minimum value of $1 \mathrm{MW}$ to protect the SESD from simultaneous charging and discharging. The minimum power value allow the SESD to provide with energy only on heavy demand load conditions.

- SESD current (ISESD) is measured and compared with the maximum allowable load current $6 \mathrm{kA}$. This condition keeps the load current below the maximum value to protect the SC.

- SC state of charge (SOC) is measured. The minimum SOC is set to $40 \%$.

If all conditions are achieved then the third rail will be fed by the SESD (SESD discharging $=\mathrm{ON}$ ).

The energy management strategy flowchart for the load control is presented in figure 7 .

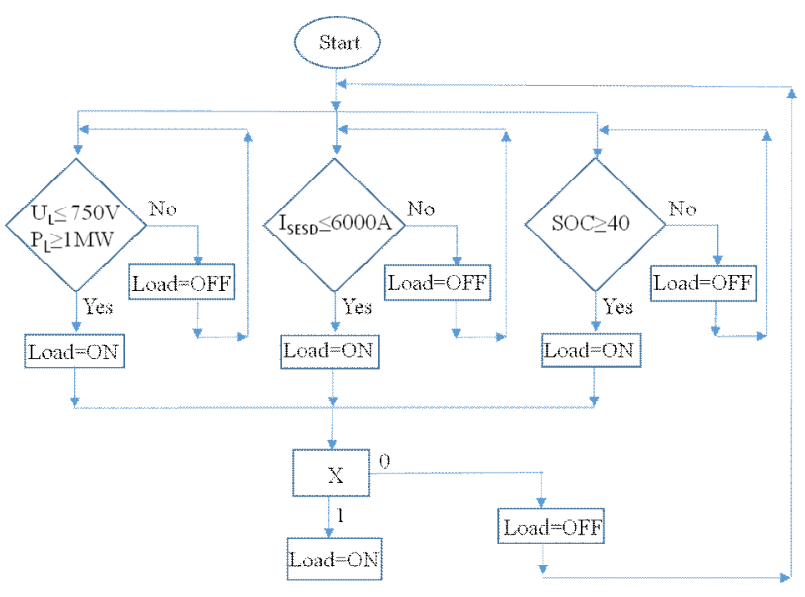

Fig. 7. Energy management strategy for discharging the SESD. 


\section{Simulation results}

Figure 8 presents the Matlab / Simulink model used to simulate the metro $750 \mathrm{~V}$ DC supply system from figure 1 with SESD installed within Substation 1. The simulated model is a single metro line with 2 trains running between Substation 1 and Substation 2. To simulate different load for each substation a resistance was designed for third rail and running rail. The total length of the line is considered $2.1 \mathrm{~km}$ and the line resistance was designed according with the train distance from the substations. The location of the train is given in table 4.

Table 4. Train location.

\begin{tabular}{|c|c|c|}
\hline $\begin{array}{c}\text { Train } \\
\text { No. }\end{array}$ & $\begin{array}{c}\text { Distance from } \\
\text { Substation 1 } \\
{[\mathbf{k m}]}\end{array}$ & $\begin{array}{c}\text { Distance from } \\
\text { Substation 2 } \\
{[\mathbf{k m}]}\end{array}$ \\
\hline 1 & 0.2 & 1.9 \\
\hline 2 & 1 & 1.1 \\
\hline
\end{tabular}

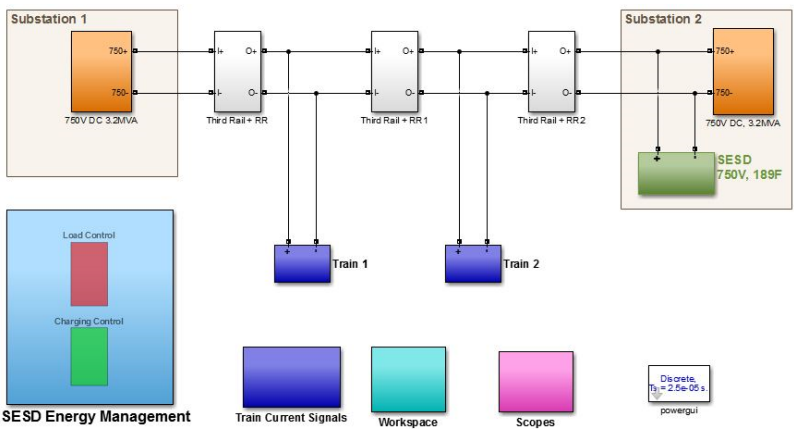

Fig. 8. Metro 750 V DC Matlab / Simulink model.

In figure 9 is presented the simulation results for the SESD installed within Substation 2 for a simulation time of 210 seconds and a step size of 0.5 seconds.

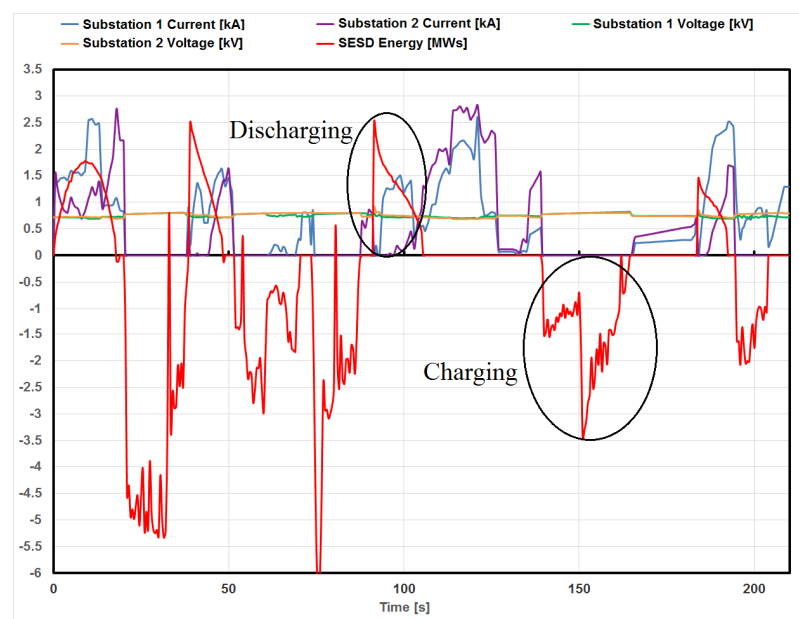

Fig. 9. SESD located within the Substation 2.

During heavy demand of traction energy the SESD successfully provides the auxiliary energy for keeping the third rail voltage stable and under the limits. The maximum discharge current is $3 \mathrm{kA}$. During braking process the SESD stores the energy with maximum charging current up to $6 \mathrm{kA}$.
In figure 11 it can be observed that the substations voltage did not exceed the $1 \mathrm{kV}$ voltage limit according with EN 50163 standard.

On figure 13 the SC SOC is charging / discharging according with the train powering or braking.

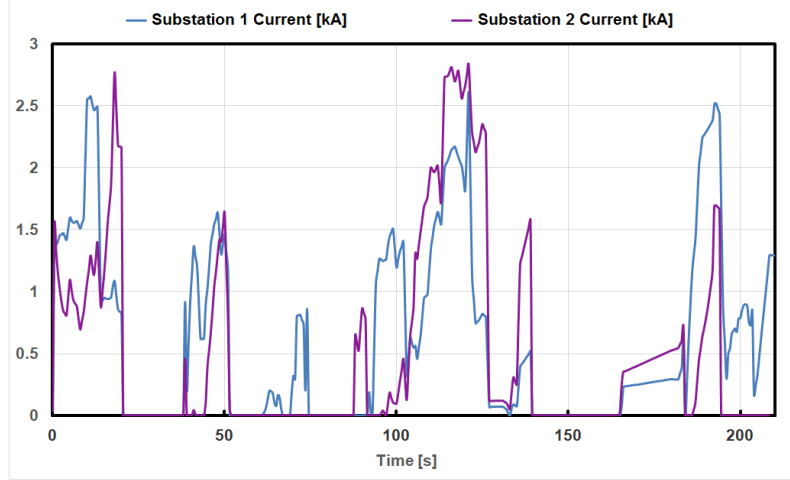

Fig. 10. Substation 1 and 2 current.

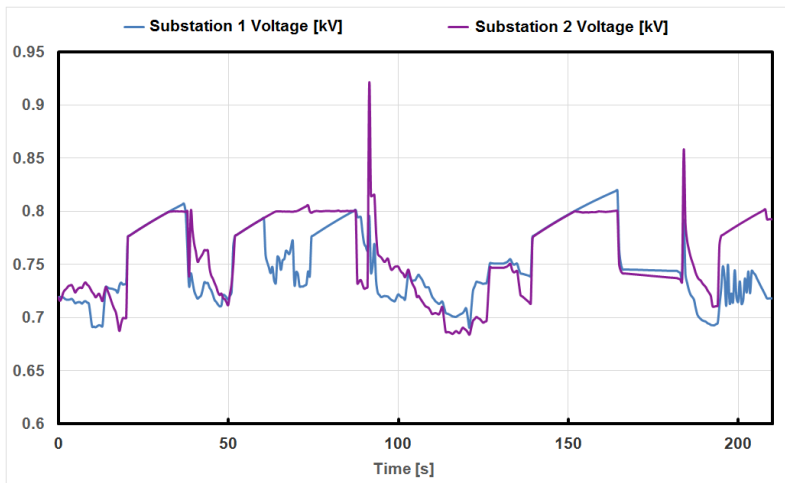

Fig. 11. Substation 1 and 2 voltage.

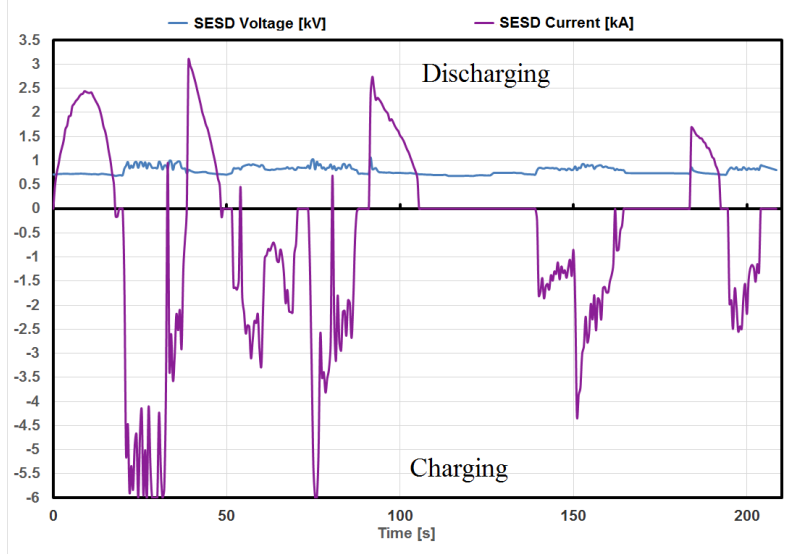

Fig. 12. SESD current and voltage.

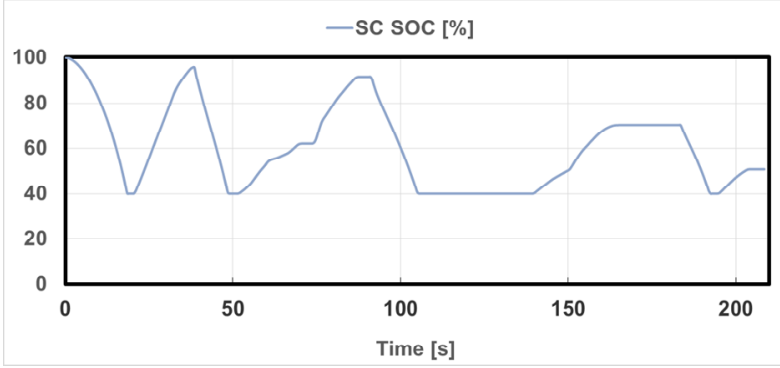

Fig. 13. SC SOC. 
From figure 14 and figure 15 it can be observed that the control system for the braking system has a good time response and is able to suppress the overvoltage during train braking. The third rail voltage is below the $1 \mathrm{kV}$ maximum allowed non-permanent voltage limit.

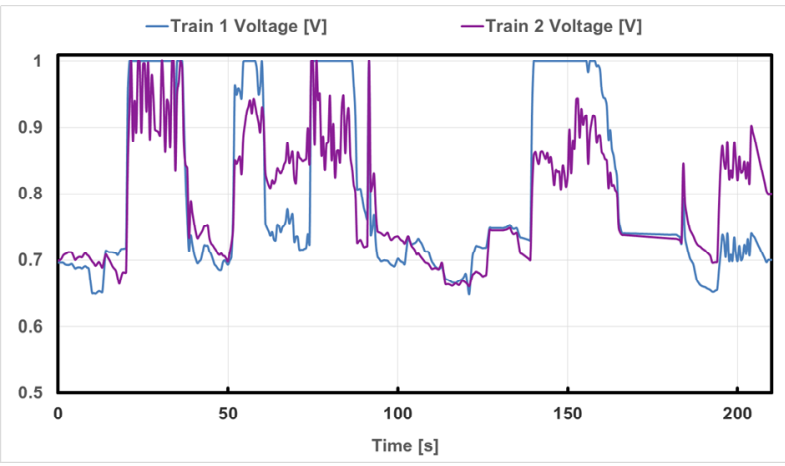

Fig. 14. Train 1 and 2 contact shoe voltage.

During braking process excessive part of the regenerated energy is lost on the braking resistors. This is due to lack of receptivity of power supply.

\section{Study case}

A study case was performed for a $8 \mathrm{~km}$ section of a metro line with a SESD installed in the mid-point between 2 traction substations (TS) distanced $3 \mathrm{~km}$ one from another. Traffic of metro trains was organized regularly with density $\mathrm{dt}=90,150,180$ and $240 \mathrm{~s}$ between trains on both directions. There were assumed 3 energy capacity of SESD with maximum charge / discharge current rated: $2.5 \mathrm{kA}$ (minimum), $4 \mathrm{kA}$ and 6 $\mathrm{kA}$ (maximum). For $\mathrm{dt}=90 \mathrm{~s} 1$ hour obtained energy savings were $0.32 \mathrm{MWh}, 0.28 \mathrm{MWh}$ and $0.18 \mathrm{MWh}$ respectively for $6 \mathrm{kA}, 4 \mathrm{kA}$ and $2.5 \mathrm{kA}$ SESD. The results of simulation of operation of SESD for traffic density $\mathrm{dt}=90 \mathrm{~s}$ and $\mathrm{dt}=240 \mathrm{~s}$ are presented in figure 15 - energy Es stored and current Is of SESD for $6 \mathrm{kA}$ SESD having $42 \mathrm{MJ}$ available energy capacity.

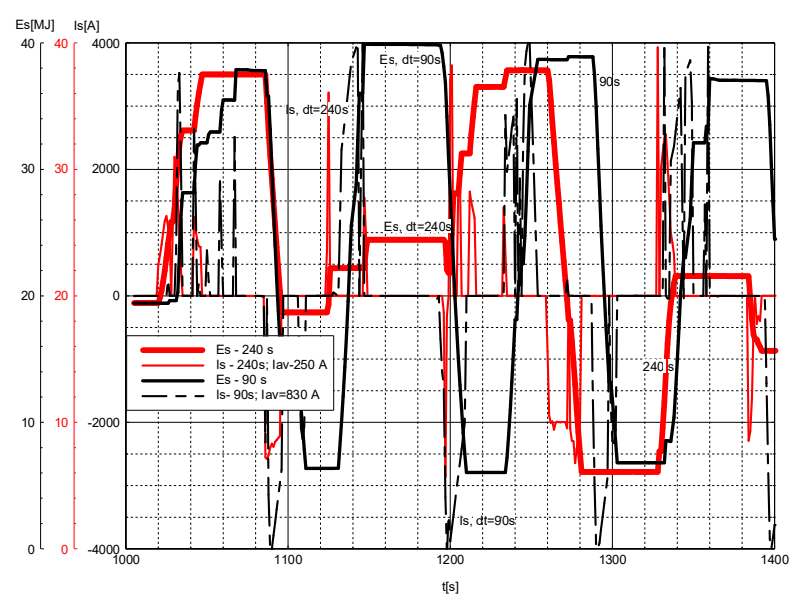

Fig. 15. Energy Es and current Is of a 6 kA SESD for $\mathrm{dt}=90 \mathrm{~s}$ and $\mathrm{dt}=240 \mathrm{~s}$.

Values of energy transferred by SESD during $6.5 \mathrm{~min}$ of simulation for $\mathrm{dt}=180 \mathrm{~s}$ was $77 \mathrm{MJ}$, while for $\mathrm{dt}=$
$240 \mathrm{~s}$ energy was $44 \mathrm{MJ}$. It gives, assuming $5.5 \mathrm{~h}$ of rush hours with traffic density $\mathrm{dt}=180 \mathrm{~s}$ and 11 hours with density $\mathrm{dt}=240 \mathrm{~s}$ about $2.4 \mathrm{MWh}$ of energy saved per working day.

Measurements taken from supercapacitors SESD installed in II Warsaw Metro line shown week-day savings around $2 \mathrm{MWh}$. Similar results were reported in [14] for high power capacity battery type SESD installed in a TS in metro line in Washington USA, with practically double value of energy saved when this SESD was installed between 2 TS.

\section{Conclusion}

In this paper a simulation of a metro rail power supply system with SESD was presented. A new dynamic energy management strategy was proposed. The strategy uses the measurements of the third rail currents and voltage and the SC SOC. The simulation results in a study case performed shown influence of density of traffic and SESD capacity on amount of braking energy savings. The simulation tools could be used for designing of the SESD parameters and location to obtain high effectiveness of its installation.

\section{References}

1. D. Vine, Transportation emissions roll over power sector emissions (Center for Climate and Energy Solutions 2016), https://www.c2es.org/2016/06/transportationemissions-roll-over-power-sector-emissions/

2. A. Szelagg, Efficiency of the regenerative braking in the electrificated rail transport, Institute of Railway Transport TABOR [Instytut Pojazdów Szynowych TABOR], 4, 9-16 (2009).

3. J. Yang, J. Zhang and P. Song, Fuzzy Energy Management for a Catenary-Battery-Ultracapacitor based Hybrid Tramway, 2nd Asia Conference on Power and Electrical Engineering (ACPEE), Shanghai, China, 1-7 (2017)

4. X. Hu, N. Murgovski, L. M. Johannesson and B. Egardt, Comparison of three electrochemical energy buffers applied to a hybrid bus powertrain with simultaneous optimal sizing and energy management. IEEE Trans Intell Transp Syst, 15, 1193-1205 (2014)

5. Z. Song, H. Hofmann, J. Li, X. Han and M. Ouyang, Optimization for a hybrid energy storage system in electric vehicles using dynamic programing approach, Applied Energy, 139, 151-162 (2015)

6. A. Chauvin, A. Hijazi, E. Bideaux and A. Sari, Combinatorial approach for sizing and optimal energy management of HEV including durability constraints, Proceeding of IEEE 24th International Symposium on Industrial Electronics (ISIE), Buzios, Brazil, 1236-1241 (2015)

7. M. Wieczorek and M. Lewandowski, A mathematical representation of an energy management strategy for hybrid energy storage system in electric vehicle and real time optimization using a genetic algorithm, Applied Energy, 192, 222-233 (2017)

8. J. Shen and A. Khaligh, A Supervisory Energy Management Control Strategy in a Battery/Ultracapacitor Hybrid Energy Storage System, 
IEEE Transactions on Transportation Electrification, 3(1), 223-232 (2015)

9. M. Bartłomiejczyk and L. Jarzębowicz, Energy savings by application of supercapacitor storage in trolleybus supplying station - analysis of experimental results, Technical Transactions electrical engineering, 1-E(2), 17-32 (2016)

10. T. Weitzel and H. C. Glock, Energy management for stationary electric energy storage systems: A systematic literature review, European Journal of Operational Research, 1-25 (2017)

11. EN 50163, Railway Applications. Supply Voltages of Traction Systems (2007)

12. Maxwell Technologies Inc., Datasheet $125 \mathrm{~V}$ Heavy Transportation Module, http://www.maxwell.com/ images/documents/125vmodule_ds_1014696-7.pdf

13. P. Radu and A. Szelag, A Cuk converter integrated with lead-acid battery and supercapacitor for stationary applications, Proceeding of IEEE 18th International Scientific Conference on Electric Power Engineering (EPE), Kouty nad Desnou, Czech Republic, 1-6 (2017)

14. M. Ouattara and Y. J. Gordon, FTA Report No. 0086, WMATA Energy Storage Demonstration Project, Final Report (June 2015) 